\title{
A FORMAÇÃO INICIAL DE PROFESSORES NA AMAZÔNIA PARAENSE: SENTIDOS ATRIBUÍDOS PELOS EGRESSOS A LICENCIATURA EM EDUCAÇÃO DO CAMPO.
}

\author{
Alessandra Sampaio Cunha ${ }^{1}$ \\ Armando de Paulo Ferreira Loureiro ${ }^{2}$ \\ Joana d'Arc de Vasconcelos Neves ${ }^{3}$
}

\begin{abstract}
RESUMO
O presente estudo investigou as representações sociais dos professores egressos do Curso de Licenciatura em Educação do Campo sobre o processo de formação inicial e os efeitos na prática docente. Para tanto, subsidiamos esse estudo no campo teórico da formação de professores do campo e no campo teórico e metodológico processual das Representações Sociais. Como instrumento fez-se uso do questionário e das entrevistas semiestruturadas. Os atores sociais desta pesquisa foram professores, egressos do curso de Licenciatura em Educação do Campo, que atuam diretamente no território do campo na Amazônia paraense, na região nordeste, no intuito de investigarmos a seguinte questão: quais sentidos os egressos desse curso atribuem ao processo de formação inicial e seus efeitos na prática docente nos contextos dos campos amazônicos? Os resultados evidenciam, que as representações sociais dos professores sobre o curso de Licenciatura em Educação do Campo se inscrevem em significados e sentido que revelam que o processo formativo vivenciado, como territorio de oportunidades - que contribuiu de forma positiva para ressignificação da prática docente, assim como, de conflitos e contradições - reafimando a luta permanente pelo Direito a educação do campo e suas especificidades. Essas imagens orientam praticas que potencializam e valorizam conhecimentos e realidades dos sujeitos, contextos e das escolas do campo da Amazônia paraense.
\end{abstract}

Palavras chave: Educação do Campo; Formação Inicial; Representações Sociais.

\begin{abstract}
The present study investigated the social representations of teachers who graduated from the Licentiate Course in Field Education on the process of initial formation and the effects on teaching practice. Therefore, we subsidize this study in the theoretical field of teacher training in the field and in the theoretical and methodological field of the Social Representations. As an instrument, the questionnaire and semi-structured interviews were used. The social actors of this research were teachers, graduates of the Degree in Field Education, who work directly in the territory of the Amazonian countryside in
\end{abstract}

\footnotetext{
${ }^{1}$ Doutora em Ciências da Educação pela Universidade de Trás-os-Montes e Alto Douro, em Portugal (2018). Mestre em Gestão de Recursos Naturais e Desenvolvimento Local na Amazônia pela Universidade Federal do Pará / NUMA (2011). Licenciada em Pedagogia pela Universidade Federal do Pará (2004). Atualmente é Técnica em Assuntos Educacionais (TAE) do Instituto Federal de Educação, Ciência e Tecnologia do Pará / Campus Bragança. Pesquisadora do Grupo de Pesquisa Educação, Trabalho, Tecnologia, Humanidades e Organização Social (ETTHOS)/ IFPA. Pesquisadora da Cátedra Paulo Freire da Amazônia do Grupo de Pesquisa Interinstitucional Paulo Freire: Diversidade e Educação (IFPA e UFPA) e GUEAJA (UFPA).

2 Armando Paulo Ferreira Loureiro. É Professor Auxiliar, Professor Auxiliar e Professor Auxiliar na Universidade de Trás-os-Montes e Alto Douro. Publicou 31 artigos em revistas especializadas e 32 trabalhos em actas de eventos, possui 15 capítulos de livros e 4 livros publicados. Possui 63 itens de produção técnica. Participou em 1 evento no estrangeiro e 13 em Portugal. Nas suas actividades profissionais interagiu com 69 colaboradores em co-autorias de trabalhos científicos.

${ }^{3}$ Doutora e Mestre em Educação pela Universidade Federal do Pará (UFPA). Professora Adjunta A da UFPA, Campus Universitário de Bragança, Faculdade de Educação. Professora do Programa de Pós-Graduação em Linguagens e Saberes na Amazônia (PPLSA), Linha de Pesquisa: Educação, Cultura e Sociedade. Graduada Plena Pedagogia pela Universidade Federal do Pará (UFPA). Pesquisadora do Grupo de Estudos e Pesquisa Educação de jovens e Adultos e Diversidade Amazônica (GUEAJA/UFPA).E-mail: jdneves@ufpa.br
} 
the northeast region, in order to investigate the following question: which directions do the graduates attribute to the process of initial training and its effects on teaching practice in the Amazonian field contexts? The results show that the social representations of the teachers about the course in Licentiate in Field Education are inscribed in meanings and meaning that reveal that the formative process experienced as a territory of opportunities - that contributed positively to the re - signification of the teaching practice, as well as conflicts and contradictions - reaffirming the permanent struggle for the right to education in the countryside and its specificities. These images guide practices that enhance and enhance the knowledge and realities of the subjects, contexts and schools of the Amazon region.

Keywords: Field Education. Initial formation. Social Representations.

\section{TECENDO OS FIOS INTRODUTÓRIOS}

A formação de Professores do Campo e os seus contributos tem se configurado como um importante campo de pesquisa no contexto educativo brasileiro para a construção e reconfiguração de politicas e sentidos sobre a educação das populaçoes que vivem em diferentes territórios do Campo. Neste sentido, o presente artigo, por compreender que as representacoes sociais orientam condutas, se propoem analisar as representações sociais de professores da região do Nordeste Paraense sobre a sua formação inicial no curso de Formação de Professores do Campo- IFPA-PA, e os seus efeitos em sua na prática pedagógica nas series finais do ensino fundamental da educação básica.

A Educação do Campo no território brasileiro, ganha uma nova perspectiva na década de 1990, quando os movimentos sociais e sindicais do campo e as próprias universidades colocaram-na em suas agendas de luta. Vista por esses coletivos, como uma categoria dialética e contra-hegemónica, passou-se a exigir uma educação para as populaçoes camponesas, ribeirinhas, pescadoras, extrativistas, quilombolas e indiginas, que se assentassem na identificação desses diferentes sujeitos, respeitando seus modos de vida e de cultura, contrapondo-se à escola rural que, historicamente numa visão uniformalizadora, descaracterizavam os modos de vida desses sujeitos.

Esses movimentos formalizaram e influenciaram politicas de formação inicial de profissionais para atuarem na diversidade dos territorios rurais brasileiros e tem provocado as Univesidades Brasileiras e Institutos Federais a se reinventarem tanto no campo da formação inicial de professores quanto na produção de conhecimentos para a Educação do Campo. Politicas como ação afirmativa para correção das desigualdades de que são vítimas as populações do campo no acesso à educação, principalmente à Educação Básica no campo, foram traduzidas no sentido de superar a precariedade das escolas do campo e da formação de seus profissionais (ARROYO, 2005). 
Embora esse movimento seja significativo, ressalta-se que os grupos de estudo e pesquisa sobre formação de Professores do Campo têm tido uma atuação tímida em comparação aos estudos de formação inicial de professores. Contudo, teóricos nesse campo, apontam a necessidade e importancia de estudos que se voltem à analises dessa política de formação inicial de Professores do Campo e os reflexos em suas práticas pedagógicas na educação básica, mais especificamente, nas escolas do campo.

Nesses termos, compreender os sentidos e significados construídos por professores, egressos do curso de Licenciatura em Educação do Campo, sobre o seu processo formativo e as implicações dessa prática nas escolas do campo na Amazônia Paraense é o que dá a tônica para opção do campo Teórico Metodológico das Representações Sociais, por se tratar de um campo que permite ao pesquisador volta-se para os conhecimentos particulares, construidos socialmente com a função de elaborar comportamentos e permitir a comunicação entre os indivíduos (MOSCOVICI, 1978), ou seja, estudo voltado ao fazer, não apenas individual, mas, sobretudo, ao fazer vivenciado em um domínio social..

Assim, a opção pelo estudo das representações sociais se justifica na mediada em se constitui um campo teorico e metodológico que permite analisar as práticas sociais caracterizadas pela complexidade de relações, em que se produz conhecimentos, ligando os sujeitos por meio das partilhas de significados. Neste sentido, a relação entre os significados e as práticas sociais, constitui-se uma das razões fundamentais para seu estudo. Em síntese, pode-se dizer que as representações sociais explicam como um grupo se apropria de um objeto social e recria coletivamente seu significado, gerando, a priori, uma orientação para sua prática e, a posteriori, uma justificativa para suas ações.

Partindo dessa premissa, esse estudo volta-se para a compreensão do sentido que a formação docente é entendida por um grupo - nesse estudo, dos sentidos construídos pelos egressos do curso de licenciatura da educação do campo -, e como estes sentidos, passam a se configurar como um sistema de regulação social que atualiza o sistema cognitivo destes professores, dentro do contexto das escolas do campo, orientando suas condutas, informações, atitudes, delimitando o universo de possibilidades dos comportamentos desses professores. (DOISE, CLEMENCE, \& LORENZI-CIOLDI, 1992).

Os sujeitos sociais deste estudo foram os professores/egressos do Curso de Licenciatura em Educação do Campo de um Campus do IFPA, localizado no interior da Amazônia Paraense, através do Programa PROCAMPO. O recorte para a seleção dos sujeitos dessa pesquida obedeceu os seguintes critérios: a) ser professor egresso da primeira turma de 
Licenciatura em Educação do Campo de um Campus do IFPA; b) Está atuando no momento da pesquisa diretamente nas escolas do campo.

A partir desses critérios, foi definido o número de sujeitos participantes desta investigação. Dos 49 professores egressos que concluíram o curso, apenas 16 cumpriam os critérios definidos anteriormente, admitindo que esses possam representar o universo investigado, servindo para estudos qualitativos. Dentre os dezesseis sujeitos, a maioria consideram-se sujeitos do campo, por morarem e trabalharem em comunidade do campo.

Como técnica de recolha de dados, utilizamos a Entrevista Semiestruturada e o Inquérito por Questionário, com perguntas fechadas, voltado para aprender informações em relação ao perfil sócio-profissional dos sujeitos.

Essas técnicas permitiram construir o corpus para análise. Este se configurou a partir da técnica de conteúdo categorial na perspectiva de Lauren Bardin (2015), que serviu de referência para a constituição das teias interpretativas que deram base para alcançar os referenciais da investigação abalizados pelos objetivos.

Para prosseguir as questões iniciais da presente investigação - a formação do professor do campo e a representação social dessa formação e as implicações na prática docente, mediante aos dados produzidos na pesquisa de campo, apresentamos as temáticas de reflexão teóricas e os entrelaços das discussões e resultados a partir considerando a tridimensionalidade de Jodellet (1989): a) Do contexto de circulação: Formação Inicial e Prática Docente dos Professores do Campo; b) Dos sentidos e significados construídos: Sobre a Licenciatura em Educação do Campo; c) das atitudes: implicações em suas práticas.

\section{PRIMEIRA DIMENSÃO: A) DO CONTEXTO DE CIRCULAÇÃO - FORMAÇÃO INICIAL E PRÁTICA DOCENTE DOS PROFESSORES DO CAMPO.}

O debate da formação inicial é marcada pela relação entre o ser e o fazer-se professor " [...] um sujeito do conhecimento, um ator que desenvolve e possui sempre teorias, conhecimentos e saberes de sua própria ação" (TARDIF, 2014, p. 234-235). Nesse sentido, na medida em que, a fundamentação teórica estreita a relação com a prática, partindo de uma reflexão sistemática, proporciona, igualmente, elementos que desenvolvem, fomentam, enriquecem e proporcionam a capacidade de contribuir para a ação docente.

O conhecimento do professor não é meramente académico, racional, feito de factos, noções e teorias, como também não é um conhecimento feito só de experiência. É um saber que consiste em gerir a informação disponível e adequá-la estrategicamente ao contexto da situação formativa, em que, em cada instante, se 
situa sem perder de vista os objetivos traçados. É um saber agir em situação (ALARCÃO, 1998, p. 104).

Contudo, o debate da formação de educadores do campo, versa antes de tudo um processo formativo que envolva principios que possibilitem o exercicio da educação libertadora que se contraponha aos processos historicos desumanidores da comunidade camponesa. Dito de outra forma, uma formação que potencialize uma educação no sentido de amplo processo de formação humana que constrói referências culturais e políticas para a intervenção das pessoas e dos sujeitos sociais na realidade.

Importa, portanto, afirmar a especificidade dos direitos coletivos, por meio de políticas afirmativas, na medida em que, de acordo com as Diretrizes Operacionais para a Educação Básica, nas escolas do campo, no seu Artigo 13, a formação dos Professores do Campo influi nas condições fundamentais para o desenvolvimento real da escola do campo e, consequentemente, dos seus sujeitos. É, por isso, necessário ter presente e reafirmar as ideias que têm sido desdobradas, nesse sentido, da diferença da proposta de formação de professores, no âmbito da Educação do Campo, relativamente à Educação Rural, bem como das políticas de formação fomentadas (ARROYO, 2007, p. 175-176).

Para Pimenta (2010), a educação é um processo de humanização. Com efeito, a formação inicial é imprescindível a uma prática pedagógica e social, que se constitui o locus da profissionalização, no quotidiano do trabalho na escola. Neste sentido, compreender a formação docente é considerar o professor um profissional da educação que trabalha com pessoas situadas em um tempo e espaço historico e cultural. O que implica que a formação inicial de professores envolva a teoria e a prática, de tal modo que, num dado momento, se torne um contínuo processo de ação-reflexão-ação, no trabalho do professor (FREIRE, 1986).

Para Arroyo, Caldart, Molina (2008), a formação de professores para atuarem em escolas do campo deve ser concebida abrangendo preocupação do professor para além dos conteúdos escolarizados e, incluir o campo social e a pauta de lutas pela sobrevivência dos diferentes sujeitos no qual a escola esteja localizada. Como nos diz Freire (1997): a) A realidade dos sujeitos como ponto de partida e chegada da prática pedagógica, b) A compreensão da incompletude dos sujeitos, que se reconhecem como inacabados em permanente processo social de busca; ou ainda, como enfatiza Nóvoa (1992) "a formação não deve se dar alheia ao território de atuação do educador .

Nesta perspectiva a formação do professor do campo deve estar articulada e sintonizada com as a matrizes culturais e as marcas identitárias dos diferentes sujeitos do campo. O que implica dizer, que o processo formativo desse profissional requer bases 
epistemológicas sólidas que permita avançar no campo das relações dos saberes e permita contribuir para a transformação social, econômica, cultural e educativa, considerando-se a educação como prática social, como um espaço de contradições e sínteses culturais.

Ainda Freire (1986, p. 37) fala "[num] a postura crítica reflexiva do professor na qual valoriza a articulação de teoria e prática, na assunção de uma práxis transformadora", e Pimenta (2011, p. 63) destaca a necessidade de "[...] partindo do interesse libertário do conhecimento de uma teoria crítica da sociedade, voltada à emancipação e libertação dos homens (humanização), tornar possível a antecipação de uma práxis educacional transformadora".

Como se pode constatar, são vários os contributos em termos das concepções e práticas vigentes referentes à formação inicial do professor como ponto de partida para uma melhoria da profissionalidade e para a ressignificação da prática docente. Relativamente a essa questão, Candau \& Moreira (2005, p. 23), consideram que, [...] "a formação continuada é necessária", [...] "de modo que articula teoria e prática na formação e na construção do conhecimento profissional do professor", bem como, diz Nóvoa (1997, p. 25) "o desenvolvimento pessoal é indissociável do desenvolvimento profissional e as instâncias formativas têm que abrir espaços para essa compreensão".

Para Arroyo (2007), o paradigma da educação do campo questiona o prototipo de profissional unico para qualquer coletivo tanto quanto as normas e diretrizes generalistas que apenas aconselham "adaptem-se" à especificidade da escola rural. Ao nível das políticas públicas direcionadas para a especificidade da docência na Educação do Campo, questionamse os currículos dos cursos de formação, bem como as instituições formadoras que assumem a responsabilidade de oferecerem cursos específicos de formação de Professores do Campo, quer via Programas, quer na forma de cursos regulares.

Neste sentido, os princípios e concepções sobre a formação do professor do campo vão de encontro às expectativas de se repensar os cursos de Licenciaturas nas instituições de ensino superior, de modo que venham a preparar profissionais da educação capazes de desenvolver práticas contra-hegemônicas e que consigam fortalecer os educandos das escolas do campo ao dar-lhes o conhecimento necessário para como nos diz Freire (1997), ajudar a formar os sujeitos capazes de fazer a transformação da sociedade, do mundo, de si mesmos.

Para Neto (2011, p.36) a concepção de educação, presente no curso de Licenciatura em Educação do Campo, "deve romper com a velha lógica capitalista de fragmentação do conhecimento no campo - com vista para a produtividade", uma vez que a intencionalidade 
do curso é trabalhar "as dimensões humanas, tendo por base a inserção crítica na realidade social" (ibid).

\section{SEGUNDA DIMENSÃO: B) DOS SENTIDOS E SIGNIFICADOS - REPRESENTAÇÕES SOBRE A LICENCIATURA EM EDUCAÇÃO DO CAMPO}

O Curso de Licenciatura em Educação do Campo do IFPA inscreve-se dentro dessa proposta inovadora de políticas de formação de professores, a partir das componentes curriculares diversificadas que abre e da possibilidade de fazer desse processo de formação um espaço de conhecimento, produção e leitura da realidade campesina diferenciada, que prepara o professor para trabalhar por áreas de conhecimento e não, apenas, com disciplinas.

O Projeto Pedagógico do Curso de Educação do Campo foi pensado e concebido para promover o desenvolvimento do campo brasileiro e voltado para a realidade dos sujeitos do campo, tendo como elementos fundamentais, o trabalho, como um princípio educativo, e a inter e transdisciplinaridade, como alternativas para a Educação do Campo.

De acordo com Rocha (2011, p. 50), a Formação Básica compreende a formação necessária para professor do campo exercer a atividade nas séries iniciais do Ensino Fundamental (confere uma habilitação de professor multidisciplinar na Educação Básica). A Formação Específica é orientada por área de conhecimento em Ciências da Vida e Natureza, ou em Ciências Sociais e Humanidades; em Línguas, Artes e Literatura ou em Matemática, nas séries finais dos ensinos Fundamental e Médio. A Formação Integradora pretende responder à questão de como uma determinada área do conhecimento pode dialogar com outras áreas, visando construção de um sistema educativo articulado com os interesses dos sujeitos do campo.

Relativamente à base curricular do curso de Licenciatura em Educação do Campo, e de acordo com a proposta aprovada pela SECAD /MEC, o curso deve formar profissionais capazes de: 1) exercer a docência multidisciplinar, a partir de uma das áreas de conhecimento; 2) participar da gestão de processos educativos escolares; 3) ter atuação pedagógica nas comunidades rurais, para além da prática escolar. Deve, igualmente, assegurar competências, capacidades, atitudes, saberes e valores, que deverão, necessariamente, fazer parte do perfil dos professores egressos do campo.

Do ponto de vista pedagógico, a formação deve preparar os licenciados no domínio das ferramentas de planeamento, gestão, desenvolvimento e avaliação dos processos de ensino-aprendizagem, e contemplar o estudo/debate sobre o currículo integrado, a pedagogia da alternância, a pesquisa e o trabalho como princípios educativos, num processo de 
construção de conhecimento realizado a partir de uma articulação integrada entre a realidade do sujeito do campo e as teorias subjacentes a cada área do conhecimento (PPC/IFPA, 2011).

Por outro lado, pode ser entendido como determinadas licenciaturas não terem currículos adequados para satisfazer as especificidades de determinadas populações de alguns territórios amazônicos, uma noção que ressalta dos depoimentos dos professores egressos, que se referem a esse aspecto como uma lacuna:

Os sentidos construidos pelos entrevistados sobre o curso, revelam o significados como: a) oportunidade no campo pessoal quanto reconhecimento profissional; b) um territorio de contradições e conflitos

Para os professores entrevistados participarem do pragrama é carregado do sentido de que o programa cumpre o seu papel ao oportunizar que pessoas do campo como eles possam acessar o nivel superior.

"[...] a formação de professor do campo pelo IFPA, no curso de Educação do
Campo, foi muito importante pra gente, muitos já tinham até desistido de estudar, ai
derepente nós podemos ter uma formação de professor, para dar aula para as
crianças e também para os jovens. Veio também ajudar e muito aos que ja
trabalhavam na escola e nao sabiam como fazer para ajudar a nossa gente,agora
podiamos organizar a escola. Ser ate coordenador. O curso veio mesmo.mudar muita
coisa na vida da gente. Da segurança na nossa comunidade para ( FALA DO
PROFESSOR)

Os discursos dos professores denotam o sentido da oportunidade que o nivel superior traz para a sua vida pessoal - possibilidade de exercer a docência nas séries iniciais do Ensino Fundamental e nas séries finais do Ensino Fundamental; assumir funções de coordenação pedagógica nas escolas do campo - como também o reconhecimento profissional.

A aposta que esses sujeitos realizaram por meio de um processo formativo, levou-os a compreensao de um processo de conquista de direito marcado pela perspctiva da (re)humanizadora fruto do saber, do ser e do estar nomento como sujeito de sua historia, rompendo a lógica mercadologica da formação para o trabalho. (MENEZES NETO, 2009)

Nessa direção o reconhecimento profissional requer uma atitude de ser no mundo a partir da participação ativa. Como destaca o entrevistado, o reconhecimento se configura numa conquista, construida pelo professor, na medida em que passa a assumir uma função de formador de outros professores, no que diz respeito à logica da Educação do Campo e aos seus princípios teórico-metodológicos, no contexto da escola em que trabalha. 
(...) essa formação é bem aceita, tanto pela secretaria, quanto pela parte pedagógica da escola, quando a gente faz palestra e mostra a experiência os outros professores para socializar aquilo que nós aprendemos (FALA DO PROFESSOR).

Não obstante este reconhecimento,é marcado pelo campo de disputas que subsistem algumas dificuldades que decorrem da transição entre um sistema de ensino onde não existia a figura do licenciado em Educação do Campo, e o atual, que reconhece este profissional, mas continua organizado de acordo com a lógica da escola urbana:

(...) A gente tem dificuldade de exercer, por ser algo novo, a gente tem dificuldade de colocar em pratica aquilo que aprende, então as vezes assim a gente se sente até meio frustrado enquanto professor, porque a gente cria uma expectativa de uma coisa e no final as coisas acabam sendo diferente, e que esse diferente acaba prejudicando o ensino em si, no caso por exemplo o Saberes da Terra. (FALA DO PROFESSOR).

Uma realidade contraditória que revela como nos diz Arroyo (2007) que os direitos não são construções acabadas, estão em permanente reconfiguração, na medida em que são construções históricas e marcadas pelas tensões sociais, políticas e culturais, refletem interesses locais, de grupos. Este depoimento permitem concluir que, apesar de se tratar de um curso pensado como formação diferenciada, encontra-se, em um territorio de disputas, que envolve sujeitos, os contextos de trabalho.

Assim, o sentido consensual, de acordo com as falas apresentadas, mostra que os professores do campo percebe-se no movimento da conquista de seus Direitos com a formação e a considera importante, apesar das dificuldades que enfrentam, e tem consciência da importância da formação para atuação enquanto sujeito de transformação das escolas do campo.

\section{TERCEIRA DIMENSÃO: C) DAS ATITUDES - IMPLICAÇÃOES EM SUAS PRÁTICAS.}

Neste estudo, a temática analítica resulta da análise do contexto dos sujeitos da pesquisa, os professores egressos da Licenciatura em Educação do Campo, do Programa PROCAMPO de um campus do Instituto Federal do Pará, que durante os quatro primeiros semestres frequentaram no formato curricular um núcleo comum; a partir do $5^{\circ}$ semestre, tiveram que optar por uma das áreas de conhecimento. Essa escolha, da inteira responsabilidade do aluno, permitiu a aquisição de uma habilitação específica, com uma carga horária equivalente para as duas áreas. 
Por outro lado, embora exista uma base comum de conhecimento que deve subsidiar o ensino de qualquer formação, é preciso reconhecer, na mesma proporção, que há especificidades que podem, inclusivamente, ajudar à independência de cada área, dentro desse campo mais amplo que é a formação desejada pelos profissionais da Educação do Campo.

$\mathrm{Na}$ fala de outros professores, observamos as imagens tecidas sobre a importância da formação para sua prática docente no contexto das escolas do campo é marcada pelo sentido do empoderamento tanto na ampliação do conhecimento quanto na sua capacidade de valorizar a cultura dos sujeitos do campo:

(...) o curso de Educação do Campo veio abranger os nossos conhecimentos, ele nos qualificou ainda mais, valorizar as culturas, apesar de ser filho do campo a gente conhecia a realidade, a gente conhecia algumas práticas, mas agora com as teorias que tivemos na academia, nos proporcionou muito mais ainda, hoje como graduados na Educação do Campo temos trabalhado valorizando a identidade desse povo, a cultura e valores. (FALA DO PROFESSOR)

(...) os conhecimentos teóricos foram fundamentais porque prática a gente já tinha, conhecia a realidade dos alunos, mas o conhecimento teórico foi fundamental. (FALA DO PROFESSOR).

Ressalta-se na fala desse professor o conhecimento como ponto de transformação de sua pratica. Conhecimento este, que o potencializa leituras e releituras da realidade do aluno, colocando desta forma, a sua formação no rompimento da praticas docentes tecnocratas e mais próxima as tensões no campo entre o latifúndio, a monocultura, o agronegócio e a agricultura familiar. A ideia do Conhecimento adquirido na formação de professores para compreensão dos territórios do campo como espaço de produção da vida, cultura, identidades, revelam uma outra dinâmica de efeitos dessa formação para a prática desse professor, ou seja, uma dimensao pedagógica onde se processa relações de saberes, no contexto escolares do campo, uma formação que potencializa a valorização da pluraliade cultural, o desenvolvimento local no processo de produção do conhecimento, conforme destaca o professor na fala a abaixo:

(...) em relação à prática, uma prática diferenciada que nós tivemos em relação ao povo do campo, a gente não só ensina como aprende com o povo do campo, e a gente leva em consideração aquilo que eles tem, a identidade que eles tem, a identidade deles dentro do campo. (FALA DO PROFESSOR)

$\mathrm{Na}$ de processos relacionais, a dinamica da postura pedagógica conquistada a partir da Licenciatura em Educação do Campo o fazer docente e marcado pela postura do reconhecimento dos/de: a) Alunos como protagonistas; b) Conhecimentos articulado ao o uso social, de forma interdisciplinar, e por áreas de conhecimento; d) que a lógica da formação 
opõe-se ao conhecimento generalista e fragmentado; e) o curso proporciona o reconhecimento dos professores que atuam no campo; f) há uma fase de transição entre o reconhecimento profissional e a manutenção das estruturas de ensino numa lógica urbana.

Nesta perspectiva a Licenciatura em Educação do Campo fomentar o conhecimento acadêmico interdisciplinar sobre as características socioculturais e ambientais que demarcam o território de existência coletiva destes sujeitos, bem como a realidade socioeducativa, comprometida com os princípios da educação emancipatória na perspetiva de Paulo Freire.

Esse movimento construtivo da formação de professores do campo vivenciado e experimentado pelos nossos entrevistado é para Molina(2010) um movimento possivel e necessário, marcado por ricas experiencias como a pesquisa na centralidade do processo educativos, oferecem ao campo da educação um caminho possivel para superar estilos homogenizadores de curriculos e formações de profisssionais da educação básica. Uma contribuição para o pensamento educacional que merece ser olhada com atenção e incorporada na formulação de políticas públicas.

\section{CONSIDERAÇÕES FINAIS}

As especificidades da formação de professores do Campo são construídas com base no movimento de disputas e contradições. É um processo que segundo Caldart (2004, p. 149) é marcada pela "luta do povo do campo por políticas públicas que garantam o seu direito a uma educação que seja no e do campo". Logo, as políticas públicas educativas direcionadas para o campo são importantes na construção e afirmação desta modalidade de educação.

Nessa perspectiva, os sentidos e significados construidos sobre o processo de formação de professores no curso Licenciatura em Educação do campo IFPA imagens de oportunidade no campo pessoal e profissional e de um territorio de contradições e conflitos e disputas.

No campo da oportunidade pessoal e profissional os professores destacam que o processo formativo vivenciado, a partir de uma formação específica, contribuiu de forma positiva para ressignificação do fazer docente articulado posturas relacionais de produção de conhecimentos que orientam práticas pedagógicas potencializadoras da dinamica de vida e cultura dos povos do campo.

Diante disso, conhecer as representações que os professores egressos construíram foi importante para a compreensão do que pensam a respeito do seu próprio processo de formação, bem como para a análise e compreensão de formação inicial de professores para 
atuarem na diversidade amazonica encontra-se no processo de conquista de direitos que ainda se encontram em construção em movimentos conflituosos e de disputas.

Desta forma reafirmamos que a Licenciatura em educação do Campo tem sido um grande desafio à melhoria da Educação do Campo. Configurando a existência de um novo perfil de professor, que se reconhece como sujeito que potencializa a transformação da realidade dos sujeitos do campo e que se opoe a formações de professores pautadas em modelos generalistas e fragmentados.

\section{REFERÊNCIAS}

Alarcão, I. Formação reflexiva de professores: estratégias de supervisão. Porto: Porto Editora, 1996.

Arroyo, M. G. Por um tratamento público da educação do campo. In: Molina, M. C., \& Azevedo de Jesus, S. M. S. (Orgs.). Contribuições para a construção de um projeto de educação do campo. Coleção Por uma Educação do Campo, nº 05, Brasília, DF: Articulação Nacional por uma Educação do Campo, 2004.

Educação de jovens-adultos: um campo de direitos e de responsabilidade pública. In: Soares, L., Giovanetti, M. A., \& Gomes, N. L. (Orgs.). Diálogos na educação de jovens e adultos. Belo Horizonte: Autêntica, 2005, pp.19-50.

Indagações sobre currículo: educandos e educadores: seus direitos e o currículo. Beauchamp, J., Pagel, S. D., \& Nascimento, A. R. (Org). Sobre Currículo: Diversidade e Currículo. Brasília: Ministério da Educação, Secretaria de Educação Básica, 2007.

A educação básica e o movimento social do campo. In: Arroyo, M. G., Caldart, R. S., \& Molina, C. (Org). Por uma educação do campo. (4a . ed.). Petropolis, RJ: Vozes, 2009, pp. 65-68.

ARROYO, Miguel Gonzalez; CALDART, Roseli Salete; MOLINA, Mônica Castagna. Por uma educação do campo. 3. ed. Petrópolis: Vozes, 2008.

Bardin, L. Análise de Conteúdo. (Reimpressão da edição revista e atualizada de 2009). Lisboa: Edições 70, 2015.

Caldart, R. S. Por Uma Educação do Campo: traços de uma identidade em construção. In: Arroyo, M. G., Caldart; R. S., \& Molina, M. C. (Orgs.). Por uma educação do campo. Petrópolis, RJ: Vozes, 2004.

JODELET, Denise. Representações sociais: um domínio em expansão. In: JODELET, D. (org.). As Representações sociais. Rio de Janeiro: Eduerj, 1989.

Doise, W., Clemence, A., \& Lorenzi-Cioldi, F. Représentations sociales et analyse de données. Grenoble: Presses Universitaires de Grenoble, 1992. 
Jodelet, D. Representações Sociais: um domínio em expansão. In: Jodelet, D. (Org.). As Representações Sociais. Rio de Janeiro: EDUERJ, 2001.

Libâneo, J. C. O professor e a construção da sua identidade profissional. In: Libâneo, J. C. Organização e gestão da escola: teoria e prática. Goiânia: Alternativa, 2001, pp. 62-71.

Freire, P. Educação e mudança. (16 a ed.). Rio de Janeiro: Paz e Terra, 1986.

. Pedagogia do Oprimido. 24. ed. Rio de Janeiro: Paz e Terra, 1997.

Molina, M. C. Reflexões sobre o significado do protagonismo dos Movimentos Sociais na construção de Políticas Públicas de Educação do Campo. In: Molina, M. C. (Org). Educação do Campo e Pesquisa: questões para reflexão II. Brasília: MDA/MEC, 2010.

. (2011). Desafios teóricos e práticos na execução das políticas públicas de educação do campo. In: Munarim, A., Beltrame, S., Conde. S. F., \& Peixer, Z. (Orgs.). Educação do Campo: reflexões e perspectivas. (2ª ed.). Florianópolis: Insular, 2011.

Moscovici, S. A representação social da psicanálise. Rio de Janeiro: Zahar, 1978.

Neto, A. J. de M. Formação de professores para a Educação do Campo: projetos sociais em disputa. In: Antunes Rocha, M. I., \& Martins, A. A. (Org.). Educação do Campo: desafios para formação de professores. (Coleção Caminhos da Educação do Campo). Belo Horizonte: Autêntica Editora, 2011.

Nóvoa, A. Diz-me como ensinas, dir-te-ei quem és e vice-versa. In: Fazenda, I. (Org.). $A$ pesquisa em educação e as transformações do conhecimento. Campinas: Papirus, 1997, p. 29-41.

Pimenta, S.G. Epistemologia da Prática: ressignificando a didática. In: Franco, M. A. S., \& Pimenta, S. G. Didática: embates contemporâneos. São Paulo: Loyola, 2010, pp. 15-41.

Panorama atual da Didática no quadro das Ciências da Educação: Educação, Pedagogia e Didática. In: Pimenta, S. G., Mazzoti, T. B., \& Nóvoa, A. (Orgs.). Pedagogia, ciências da educação? (6. ${ }^{\mathrm{a}}$ ed.). São Paulo: Cortez, 2011.

Rocha, M. I. A., \& Martins, A. A. M. (Orgs). Educação do campo: desafios para a formação de professores. ( $2^{\mathrm{a}}$ ed.). Belo Horizonte: Autentica Editora (Coleção Caminhos da Educação do Campo 1), 2011.

Schmied-Kowarzik, W. Pedagogia dialética: de Aristóteles a Paulo Freire. São Paulo: Brasiliense, 1983.

Tardif, M. Saberes docentes e formação profissional. (17ª ed.). Petrópolis, RJ: Vozes, 2014. 
Recebido em 23.02.2019

Aprovado em 11.04.2019 